\title{
The Effects of Trait Rumination and Reflection on Mental Health among Japanese University Athletes
}

\author{
Shohei Yamakoshi ${ }^{1}$, Hironobu Tsuchiya ${ }^{2}$ \\ ${ }^{1}$ Graduate School of Osaka University of Health and Sport Sciences, Osaka, Japan \\ ${ }^{2}$ Osaka University of Health and Sport Sciences, Osaka, Japan \\ Email: 214d07@ouhs.ac.jp
}

Received 14 March 2016; accepted 17 April 2016; published 20 April 2016

Copyright (C) 2016 by authors and Scientific Research Publishing Inc.

This work is licensed under the Creative Commons Attribution International License (CC BY). http://creativecommons.org/licenses/by/4.0/

(c) (i) Open Access

\begin{abstract}
The purpose of this study was to use structural equation modeling to examine the effects of trait rumination and reflection on stress response and subjective well-being among Japanese university athletes. One hundred and eighty-two Japanese university athletes (114 males, 68 females, mean age $=20.15$ years) participated. Trait rumination was positively associated with stress response and negatively associated with subjective well-being. On the other hand, trait reflection showed a negative association with stress response and a positive association with subjective well-being. In order to develop effective interventions for athletes high in rumination and/or low in reflection, future research should examine the mechanism that explains the different effects of rumination and reflection on athlete mental health.
\end{abstract}

\section{Keywords}

Trait Rumination, Trait Reflection, Stress Response, Subjective Well-Being

\section{Introduction}

Past research has assessed mental health problems in athletes, given that participating in sport often places the athlete under considerable physical and psychological stressors (Baker, Cobley, \& Fraser-Thomas, 2009; Côté, Lidor, \& Hackfort, 2009; Appleton, Hall, \& Hill, 2009). Athletes have reported a variety of stressors including injury, negative relationships with teammates/coaches, performance slump, pressure to perform well, difficulties balancing sport and non-sport commitments, and life direction concerns (Noblet \& Gifford, 2002; Noblet, Rodwell, \& McWilliams, 2003). However, recent studies have revealed that athletes experienced positive changes 
and growth as a consequence of their struggles (Galli \& Vealey, 2008; Galli \& Reel, 2012). These studies imply that although there are considerable intense stressors, some athletes successfully manage to deal with the stressors and experience positive changes, whereas others experience poor mental health. It is important to identify such individual differences in vulnerability to mental health problems among athletes.

One of the factors that could explain such individual differences in mental health is athletes' personality. Personality is defined as characteristic patterns of thoughts, feelings and behaviours over time and across situations (Connor-Smith \& Flachsbart, 2007). Thus, when athletes experience a stressor, personality certainly influences how they behave. In the sport psychology literature, personality traits such as optimism, pessimism and the Big Five personality dimensions (Neuroticism, Extraversion, Agreeableness, Consciousness and Openness to Experience) have been shown to influence the appraisal of the stressor, the use of certain coping strategies, and the effectiveness of these coping strategies (Grove \& Heard, 1997; Nicholls, Polman, Levy, \& Backhouse, 2008; Allen, Greenlees, \& Jones, 2011; Kaiseler, Polman, \& Nicholls, 2012). Consequently, for developing effective interventions for athletes who have mental health issues, it is important to investigate the association between personality and mental health.

Recently, a large body of clinical psychology research has suggested that trait rumination and reflection might be important dispositional variables that could explain individual differences in mental health (Trapnell \& Campbell, 1999; Takano \& Tanno, 2009). Trapnell and Campbell (1999) distinguished between rumination and reflection subtypes of trait self-focus, based on neurotic and intellective motives. Rumination is a maladaptive form of self-focus and has been defined as repetitive, aversive and uncontrollable thought that is motivated by perceived threats, losses, or injustices to the self (Trapnell \& Campbell, 1999). Rumination has been shown to be positively associated with a number of negative effects such as depression (Trapnell \& Campbell, 1999; Takano \& Tanno, 2009), anxiety (Trapnell \& Campbell, 1999), and anger (Rusting \& Nolen-Hoeksema, 1998). Moreover, rumination is also associated with diminished life satisfaction and subjective well-being (Elliot \& Coker, 2008; Harrington \& Loffredo, 2010).

On the other hand, trait reflection has been defined as chronic self-focus that involves playful exploration of novel, unique, or alternative self-perceptions, motivated by curiosity and pleasurable, intrinsic interest in philosophical thinking (Trapnell \& Campbell, 1999). Reflection is an adaptive form of self-focus and previous studies have suggested that reflection shows a negative association with depression (Takano \& Tanno, 2009) and a positive association with subjective well-being (Elliot \& Coker, 2008).

The inverse effects of trait rumination and reflection on mental health might be due to their different effects on problem-solving. Because individuals high in rumination tend to focus on negative information after stressful events occur, they may perceive an event more negatively and fail to employ effective coping strategies. A number of studies have shown that rumination is associated with negatively biased interpretation of problematic situations, pessimistic predictions about one's future (Lyubomirsky \& Nolen-Hoeksema, 1995; Lyubomirsky, Caldwell, \& Nolen-Hoeksema, 1998), and disengagement coping strategies (Burwell \& Shirk, 2007). In the sport psychology literature, disengagement (also labeled avoidance) coping strategies have been shown to be associated with negative affect among athletes (Crocker \& Graham, 1995; Ntoumanis \& Biddle, 1998; Ntoumanis, Biddle, \& Haddock, 1999). As mentioned before, athletes are exposed to considerable stress, and consequently athletes need to be able to cope with stressors in order to maintain durable mental health. Thus, highly ruminative athletes might be at greater risk of experiencing poor mental health due to problem solving deficits.

Reflection might enhance mental health through its positive effect on problem-solving. Because reflection is curiosity motivated self-focus, it may assist individuals to think about a situation in a number of different ways. In turn, it may help a person to engage in active attempts to change stressful circumstances. Previous studies suggested that reflection is associated with coping strategies which are aimed at changing the situation (Burwell \& Shirk, 2007). Such problem-focused coping strategies tend to be correlated with positive affect among athletes (Crocker \& Graham, 1995; Ntoumanis \& Biddle, 1998; Ntoumanis et al., 1999). Therefore, athletes high in reflection may be better able to cope effectively with stressors, which in turn help an athlete to maintain in a healthy condition.

Given that the mental health of athletes might depend on the capacity to cope effectively with stressors, with trait rumination and reflection expected to have different effects on problem-solving abilities, these disposal variables would be expected to play an important role in influencing the mental health of athletes. However, the majority of studies of rumination and reflection have examined non-athletes, and it is thus unclear whether rumination and reflection influence the mental health of athletes in the expected directions. Thus, the aim of this 
study was to examine the effects of trait rumination and reflection on mental health among Japanese university athletes. In addition, Kato (2001) suggested that in order to maintain high levels of mental health, the level of stress response (e.g., anxiety, anger and depression) should be low and the level of SWB should be high. Therefore, this study used stress response and SWB as indicators of mental health.

\section{Methods}

\subsection{Participants}

Random sampling was used. One hundred and eighty-two Japanese university athletes (114 males, 68 females) completed the questionnaires in April 2015. The mean age was 20.15 years $(\mathrm{SD}=0.88)$. Participants were recruited from a wide variety of team and individual sports, including soccer $(n=35)$, rugby $(n=9)$, ultimate $(n=$ $5)$, handball $(n=29)$, baseball $(n=19)$, American football $(n=4)$, basketball $(n=8)$, field hockey $(n=2)$, soft tennis $(n=3)$, dance $(n=2)$, volleyball $(n=5)$, tennis $(n=3)$, lacrosse $(n=4)$, badminton $(n=1)$, swimming $(n$ $=10)$, life guarding $(n=6)$, kendo $(n=8)$, track and field $(n=16)$, boxing $(n=1)$, judo $(n=3)$, baton twirling $(n$ $=2$ ), gymnastics $(n=4)$, and nihonkempo $(n=1)$. Competitive level of participants differed, from competing at national levels $(n=147)$ to regional levels $(n=35)$. The athletes had been training an average of 10 hours per week.

\subsection{Measures}

\subsubsection{Trait Rumination and Trait Reflection}

The Japanese version of the Rumination-Reflection Questionnaire (RRQ; Takano \& Tanno, 2008) was used to measure trait rumination and reflection. An example item from the Rumination subscale is "Often I'm playing back over in my mind how I acted in a past situation" and an example item of the Reflection subscale is "I love analyzing why I do things". The Japanese version of RRQ consists of 24 items and responses were measured on a five-point scale ranging from 1 (strongly disagree) to 5 (strongly agree). There is evidence of good reliability ( $\alpha=0.89$ for rumination, $\alpha=0.89$ for reflection) and validity (Takano \& Tanno, 2008).

\subsubsection{Stress Response}

The stress response scale-18 (SRS-18; Suzuki, Shimada, Miura, Katayanagi, Umano, \& Sakano, 1997) was used. The SRS-18 consists of 18 items with responses measured on a four-point scale ranging from 0 (no stress at all) to 3 (high stress). The SRS-18 has three subscales: "Depression-Anxiety", "Irritability-Anger" and "Helplessness". Example items from each subscale include "I am worrying", "I am feeling anger" and "I am not able to concentrate", respectively. A previous study indicated high reliability ( $\alpha=0.88$ for Depression-Anxiety, $\alpha=$ 0.87 for Irritability-Anger, $\alpha=0.82$ for Helplessness) and validity (Suzuki et al., 1997).

\subsubsection{Subjective Well-Being}

The subjective well-being scale (SWBS; Ito, Sugara, Ikeda, \& Kawaura, 2003) was used to measure SWB. The SWBS was developed by modifying the original Subjective Well-Being Inventory (SUBI) (Sell \& Nagpal, 1992). The SWBS consists of 12 items, with each item rated on a 4-point scale from 1 (not at all, never, etc.) to 4 (very much, always, etc). The SWBS has four subscales: "Satisfaction", "Confidence", "Achievement" and "Disappointment". All items of the "Disappointment" subscale were reversed items. Example items from each subscale are "Do you think your life is enjoyable?", "Do you have confidence in coping effectively with the things that you do not wish to happen?", "How much do you feel you succeeded?" and "Are you worrying about the future?" respectively. Past research has shown adequate reliability ( $\alpha=0.84$ for the scale) and validity (Ito et al., 2003).

\subsection{Procedure}

This study received approval from the university's research ethics committee (data of approval, 20 April 2015). Participants were recruited from university sport clubs in Japan. The first author visited clubs and also lectured at the university to recruit participants for this study. Before completing the questionnaires, all participants signed an informed consent form and were informed that all answers provided would remain anonymous. Instructions regarding how to complete the questionnaires were provided orally and participants were encouraged 
to ask questions if needed. Participants completed the questionnaires in the presence of the researcher. Completion of the questionnaires took approximately 15 minutes.

\section{Results}

\subsection{Descriptive Statistics and Correlations}

Table 1 shows means, standard deviations, and correlations among study variables. Rumination was associated with all stress response subscales (Depression-Anxiety, $r=0.41, p<0.001$; Irritability-Anger, $r=0.33, p<$ 0.001 ; Helplessness, $r=0.40, p<0.001)$ but was not associated with any of the SWB subscales $(r=-0.08$ $0.02 ; p \mathrm{~s}>0.10)$. On the other hand, trait reflection was associated with two SWB subscales (Confidence, $r=$ $0.24, p=0.001$; Achievement, $r=0.17, p=0.023)$ but was not associated with any stress response subscales $(r$ $=-0.02-0.06 ; p \mathrm{~s}>0.10$ ). In addition, consistent with previous studies (e.g., Trapnell \& Campbell, 1999; Takano \& Tanno, 2009), there was a positive association between trait rumination and reflection $(r=0.38, p<$ $0.001)$. Furthermore, all stress response subscales were negatively correlated with all SWB subscales $(r=-0.23$ $-0.50 ; p \mathrm{~s}<0.01)$.

\subsection{Effects of Trait Rumination and Reflection on Stress Response and SWB}

Structural equation modeling (SEM) analysis was conducted in order to examine the effects of trait rumination and reflection on stress response and SWB. Rumination and reflection were represented as measured variables, while stress response and SWB were represented as latent variables based on SRS-18 and SWBS dimensional scores. Furthermore, as correlational analysis showed a significant positive relationship between rumination and reflection, a path connecting rumination and reflection was added to indicate those variables as a covariate relationship. In addition, because Kato (2001) proposed stress response and SWB as negative and positive indicators of mental health respectively, and given that correlational analysis revealed that all stress response subscales were negatively associated with all SWB dimensions, a path was added between stress response and SWB error variables to indicate covariance. The model demonstrated a good fit with the sample data $\left(X^{2}=33.098(p=\right.$ $0.079), \mathrm{GFI}=0.961, \mathrm{AGFI}=0.923, \mathrm{CFI}=0.981, \mathrm{RMSEA}=0.049$ ).

The standardized path coefficients reported in Figure 1 indicate that rumination is positively associated with stress response $(\beta=0.53, p<0.01)$ and negatively associated with SWB $(\beta=-0.20, p<0.05)$. On the other hand, reflection was negatively associated with stress response $(\beta=-0.18, p<0.05)$ and positively associated with SWB $(\beta=0.34, p<0.01)$.

\section{Discussion}

The aim of this study was to examine the effects of trait rumination and reflection on mental health among Japanese university athletes. This study found that trait rumination has a maladaptive effect on mental health. In

Table 1. Means and standard deviations for and correlations among study variables.

\begin{tabular}{|c|c|c|c|c|c|c|c|c|c|c|}
\hline & Variable & 1 & 2 & 3 & 4 & 5 & 6 & 7 & 8 & 9 \\
\hline \multirow{2}{*}{ Self-Focus } & 1 Rumination & & & & & & & & & \\
\hline & 2 Reflection & $0.38^{* *}$ & & & & & & & & \\
\hline \multirow{3}{*}{ Stress Response } & $3 \mathrm{D}-\mathrm{A}$ & $0.41^{* *}$ & 0.06 & & & & & & & \\
\hline & $4 \mathrm{I}-\mathrm{A}$ & $0.33^{* *}$ & -0.01 & $0.69^{* *}$ & & & & & & \\
\hline & 5 Helplessness & $0.40^{* *}$ & -0.02 & $0.75^{* *}$ & $0.64^{* *}$ & & & & & \\
\hline \multirow{6}{*}{$\begin{array}{l}\text { Subjective } \\
\text { Well-Being }\end{array}$} & 6 Satisfaction & 0.02 & 0.09 & $-0.29^{* *}$ & $-0.30^{* *}$ & $-0.29^{* *}$ & & & & \\
\hline & 7 Confidence & -0.08 & $0.24^{* *}$ & $-0.39^{* *}$ & $-0.32^{* *}$ & $-0.50^{* *}$ & $0.37^{* *}$ & & & \\
\hline & 8 Achievement & -0.02 & $0.17^{*}$ & $-0.25^{* *}$ & $-0.26^{* *}$ & $-0.26^{* *}$ & $0.39^{* *}$ & $0.56^{* *}$ & & \\
\hline & 9 Disappointment & -0.07 & 0.09 & $-0.24^{* *}$ & $-0.23^{* *}$ & $-0.29^{* *}$ & $0.33^{* *}$ & $0.35^{* *}$ & $0.28^{* *}$ & \\
\hline & Mean & 38.29 & 37.39 & 5.57 & 5.87 & 6.28 & 9.29 & 8.61 & 8.46 & 7.75 \\
\hline & SD & 6.37 & 6.33 & 4.47 & 4.26 & 4.39 & 1.57 & 1.72 & 1.70 & 1.49 \\
\hline
\end{tabular}

${ }^{* *} p<0.01,{ }^{*} p<0.05$, D-A, Depression-Anxiety; I-A, Irritability-Anger. 


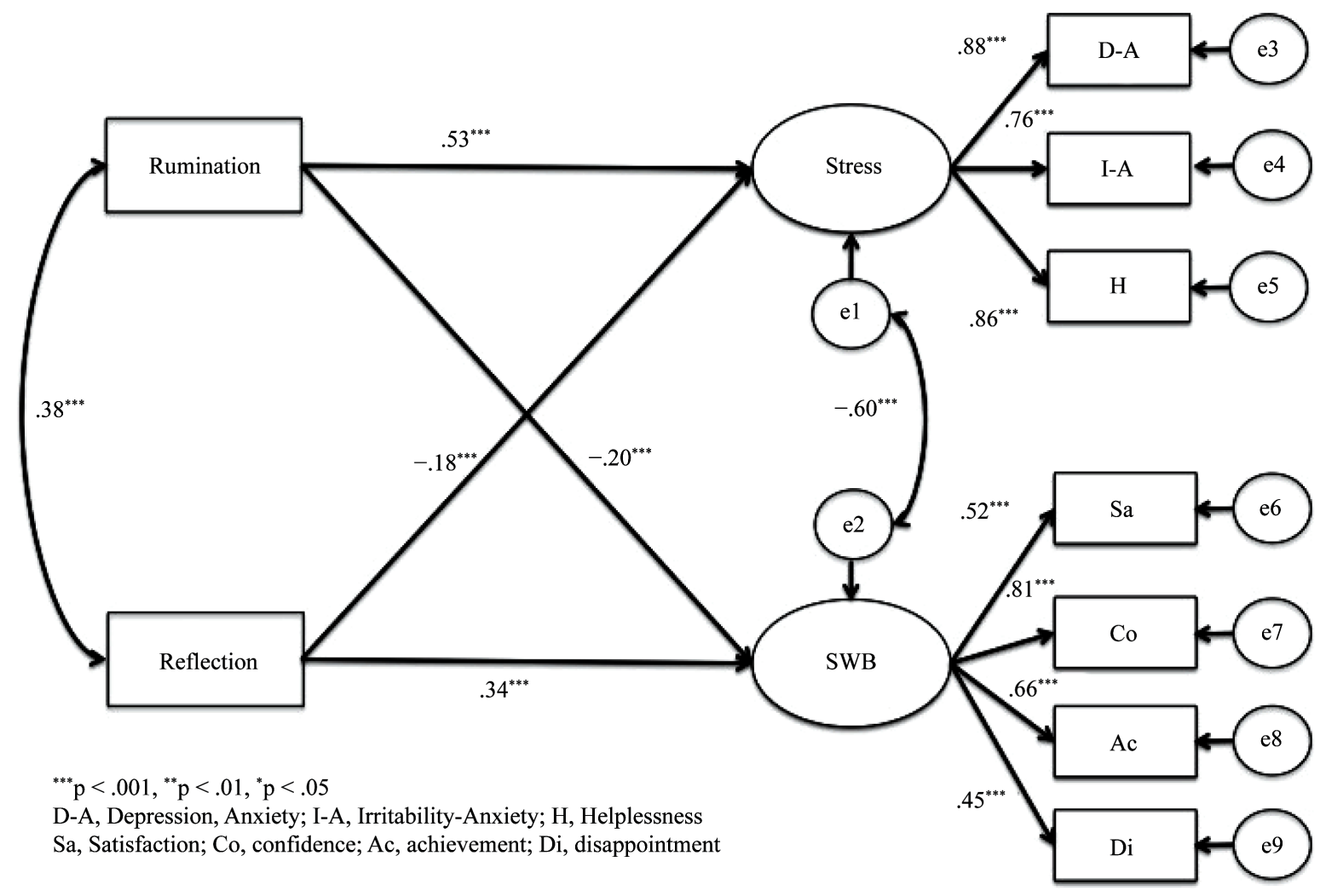

Figure 1. Effect of trait rumination and reflection on stress response and SWB.

particular, rumination was positively associated with stress response and negatively associated with SWB. These findings are consistent with previous research conducted with non-athletes (Trapnell \& Campbell, 1999; Takano \& Tanno, 2009; Rusting \& Nolen-Hoeksema, 1998; Elliot \& Coker, 2008; Harrington \& Loffredo, 2010). Rumination is characterized by focusing attention on self-relevant negative information after stressful events occur. Consequently, athletes high in rumination might appraise stressful situations as more severe, such that they are less likely to take action to change their situation. Previous studies showed that rumination was associated with a negatively biased interpretation of problematic situations and use of disengagement coping strategies (Lyubomirsky \& Nolen-Hoeksema, 1995; Lyubomirsky et al., 1998; Burwell \& Shirk, 2007). Disengagement coping has been generally shown to be associated with negative affect among athletes (Crocker \& Graham, 1995; Ntoumanis \& Biddle, 1998; Ntoumanis et al., 1999). Thus, ruminative athletes may have difficulty managing stress responses because they tend to interpret situations negatively and to cope less effectively with stressors.

Moreover, the observed negative association between rumination and SWB might be because individuals high in rumination are likely to perceive themselves more negatively. Past research suggested that self-esteem is an important factor for athletes in achieving high levels of well-being (Lundqvist, 2011), and that rumination is associated with negative self-evaluation, including self-blame and self-criticism (Lyubomisky, Tucker, Caldwell, $\&$ Berg, 1999), and low levels of self-esteem and self-acceptance (Luyckx, Soenens, Berzonsky, Smits, Goossens, \& Vansteenkiste, 2007; Takano, Sakamoto, \& Tanno, 2012; Harrington \& Loffredom, 2010). Thus, because athletes high in rumination evaluate themselves more negatively, they might have low SWB.

The present study also found that trait reflection had an adaptive effect on mental health among Japanese university athletes. In particular, reflection was negatively associated with stress response and positively associated with SWB. These findings are similarly consistent with previous research conducted with non-athletes (Takano \& Tanno, 2009; Elliot \& Coker, 2008). Reflection may facilitate individuals to consider new perspectives regarding stressful situations, which may help athletes to better manage stress responses. Jones, Papadakis, Hogan, \& Strauman (2011) examined the role of trait rumination and reflection in the relationship between promotion goal failure and depressive symptoms. This study indicated that higher levels of promotion goal failure were associated with greater depressive symptoms for individuals high in rumination. However, among in- 
dividuals high in reflection, promotion goal failure was not associated with greater depressive symptoms. Therefore, Jones et al., (2011) suggested that highly reflective individuals might be able to take a more positive view of their failures. In addition, reflection was associated with problem-focused coping strategies such as problem-solving and cognitive restructuring (Burwell \& Shirk, 2007). These coping strategies have been found to predict positive affect among athletes (Crocker \& Graham, 1995; Ntoumanis \& Biddle, 1998; Ntoumanis et al., 1999). Therefore, athletes high in reflection may be able to view a stressful situation more positively and cope effectively with stressors.

Furthermore, the observed positive association between reflection and SWB might be because individuals high in reflection are likely to evaluate themselves more positively. Previous studies examining non-athletes have suggested that reflection is associated with positive self-evaluation, including self-esteem and self-acceptance (Takano et al., 2012; Trapnell \& Campbell, 1999). As mentioned before, self-esteem is an important factor for athletes to achieve high well-being (Lundqvist, 2011). Therefore, athletes high in reflection might be more likely to achieve high SWB, because they might be able to perceive themselves more positively.

There are a number of directions for future research. Firstly, because the present study was cross-sectional in nature, a possible causal relationship between rumination/reflection and mental health remains to be clarified. Prospective longitudinal studies are required to examine such an association. Secondly, the magnitude of the effects observed here might be different according to sport-specific factors such as type of sport. Previous studies have suggested that rumination is associated with poor interpersonal problem-solving (Lyubomisky \& Nolen-Hoeksema, 1995), while reflection is associated with effective interpersonal skills such as adequate self-disclosure (Takano et al., 2012). Interpersonal relationships might be more important for team sports in order to achieve optimal mental health, compared to individual sports. Thus, the effect of rumination and reflection on mental health might be different across these types. Future research should examine the role of sportspecific factors such as type of sport and competitive level of athletes on the effect of rumination/reflection on mental health among athletes.

The practical implication of this study is that coaches and applied sport psychologists should be concerned with athletes high in rumination and/or low in reflection, as those athletes are more likely to suffer from poor mental health. In order to develop specific interventions for those athletes in order to achieve high mental health, future research should examine how trait rumination and reflection influence the mental health among athletes. Previous studies conducted with non-athletes revealed that trait rumination and reflection might influence appraisal of stressful situations and use of certain coping strategies (Lyubomirsky \& Nolen-Hoeksema, 1995; Lyubomirsky et al., 1998; Burwell \& Shirk, 2007). However, it is unclear whether this is also the case in the sport domain. Therefore, by examining possible mechanisms underlying the rumination/reflection - mental health relationship, we can better understand which aspects of athletes' functioning should serve as intervention targets (for example, changing the appraisal of the stressor and/or the use of certain coping strategies).

\section{Conclusion}

In conclusion, this study found that rumination and reflection showed different associations with mental health in a sample of Japanese university athletes. In particular, rumination was positively associated with stress response and negatively associated with SWB. On the other hand, reflection had a negative effect on stress response and a positive effect on SWB. The present findings suggest that athletes high in rumination and /or low in reflection should be a focus of interventions. In order to develop interventions for such athletes, future research should investigate psychological mechanisms that might explain the effects of rumination and reflection on the mental health of athletes.

\section{References}

Allen, M. S., Greenlees, I., \& Jones, M. (2011). An Investigation of the Five-Factor Model of Personality and Coping Behaviour in Sport. Journal of Sports Sciences, 29, 841-850. http://dx.doi.org/10.1080/02640414.2011.565064

Appleton, P. R., Hall, H. K., \& Hill, A. P. (2009). Relations between Multidimensional Perfectionism and Burnout in Junior-Elite Male Athletes. Psychology of Sport and Exercise, 10, 457-465. http://dx.doi.org/10.1016/j.psychsport.2008.12.006

Baker, J., Cobley, S., \& Fraser-Thomas, J. (2009). What Do We Know about Early Sport Specializations? Not Much! High Ability Studies, 20, 77-90. http://dx.doi.org/10.1080/13598130902860507 
Burwell, R. A., \& Shirk, S. R. (2007). Subtypes of Rumination in Adolescence: Associations between Brooding, Reflection, Depressive Symptoms, and Coping. Journal of Clinical Child and Adolescent Psychology, 36, 56-65.

http://dx.doi.org/10.1080/15374410709336568

Connor-Smith, J. K., \& Flachsbart, C. (2007). Relations between Personality and Coping: A Meta-Analysis. Journal of Personality and Social Psychology, 93, 1080-1107. http://dx.doi.org/10.1037/0022-3514.93.6.1080

Côté, J., Lidor, R., \& Hackfort, D. (2009). To Sample or to Specialize? Seven Postulates about Youth Sport Activities That Lead to Continued Participation and Elite Performance. International Journal of Sport and Exercise Psychology, 7, 7-17. http://dx.doi.org/10.1080/1612197X.2009.9671889

Crocker, P. R. E., \& Graham, R. (1995). Coping by Competitive Athletes with Performance Stress: Gender Differences and Relationships with Affect. The Sport Psychologist, 9, 325-338.

Elliot, I., \& Coker, S. (2008). Independent Self-Construal, Self-Reflection, and Self-Rumination: A Path Model for Predicting Happiness. Australian Journal of Psychology, 60, 127-134. http://dx.doi.org/10.1080/00049530701447368

Galli, N., \& Reel, J. J. (2012). "It Was Hard, But It Was Good”: A Qualitative Exploration of Stress-Related Growth in Division I Intercollegiate Athletes. Qualitative Research in Sport, Exercise and Health, 4, 297-319. http://dx.doi.org/10.1080/2159676X.2012.693524

Galli, N., \& Vealey, R. S. (2008). Bouncing Back from Adversity: Athletes' Experiences of Resilience. The Sport Psychologist, 22, 316-335.

Grove, J. R., \& Heard, N. P. (1997). Optimism and Sport Confidence as Correlates of Slump-Related Coping among Athletes. Sport Psychologist, 11, 400-410.

Harrington, R., \& Loffredo, D. A. (2010). Insight, Rumination, and Self-Reflection as Predictors of Well-Being. The Journal of Psychology, 145, 39-57. http://dx.doi.org/10.1080/00223980.2010.528072

Jones, N. P., Papadakis, A. A., Hogan, C. M., \& Strauman, T. J. (2009). Over and over Again: Rumination, Reflection, and Promotion Goal Failure and Their Interactive Effects on Depressive Symptoms. Behaviour Research and Therapy, 47, 254-259. http://dx.doi.org/10.1016/j.brat.2008.12.007

Ito, Y., Sugara, J., Ikeda, M., \& Kawaura, Y. (2003). Reliability and Validity of Subjective Well-Being Scale. The Japanese Journal of Psychology, 74, 276-281. (In Japanese) http://doi.org/10.4992/jipsy.74.276

Kaiseler, M., Polman, R. C., \& Nicholls, A. R. (2012). Effects of the Big Five Personality Dimensions on Appraisal Coping, and Coping Effectiveness in Sport. European Journal of Sport Science, 12, 62-72.

http://doi.org/10.1080/17461391.2010.551410

Kato, T. (2001). Interpersonal Stress. Japanese Journal of Educational Psychology, 49, 295-304. (In Japanese) http://doi.org/10.5926/jjep1953.49.3_295

Lundqvist, C. (2011). Well-Being in Competitive Sports-The Feel-Good Factor? A Review of Conceptual Considerations of Well-Being. International Review of Sport and Exercise Psychology, 4, 109-127. http://doi.org/10.1080/1750984X.2011.584067

Luyckx, K., Soenens, B., Berzonsky, M. D., Smits, I., Goossens, L., \& Vansteenkiste, M. (2007). Information-Oriented Identity Processing, Identity Consolidation, and Well-Being: The Moderating Role of Autonomy, Self-Reflection, and SelfRumination. Personality and Individual Differences, 43, 1099-1111. http://doi.org/10.1016/j.paid.2007.03.003

Lyubomirsky, S., \& Nolen-Hoeksema, S. (1995). Effects of Self-Focused Rumination on Negative Thinking and Interpersonal Problem Solving. Journal of Personality and Social Psychology, 69, 176-190.

http://dx.doi.org/10.1037/0022-3514.69.1.176

Lyubomirsky, S., Caldwell, N. D., \& Nolen-Hoeksema, S. (1998). Effects of Ruminative and Distracting Responses to Depressed Mood on Retrieval of Autobiographical Memories. Journal of Personality and Social Psychology, 75, 166-177. http://dx.doi.org/10.1037/0022-3514.75.1.166

Lyubomirsky, S., Tucker, K. L., Caldwell, N. D., \& Berg, K. (1999). Why Ruminators Are Poor Problem Solvers: Clues from the Phenomenology of Dysphoric Rumination. Journal of Personality and Social Psychology, 77, 1041-1060. http://dx.doi.org/10.1037/0022-3514.77.5.1041

Nicholls, A. R., Polman, R. C., Levy, A. R., \& Backhouse, S. H. (2008). Mental Toughness, Optimism, Pessimism, and Coping among Athletes. Personality and Individual Differences, 44, 1182-1192. http://dx.doi.org/10.1016/j.paid.2007.11.011

Noblet, A. J., \& Gifford, S. M. (2002). The Sources of Stress Experienced by Professional Australian Footballers. Journal of Applied Sport Psychology, 14, 1-13. http://dx.doi.org/10.1080/10413200209339007

Noblet, A., Rodwell, J., \& McWilliams, J. (2003). Predictors of the Strain Experienced by Professional Australian Footballers. Journal of Applied Sport Psychology, 15, 184-193. http://dx.doi.org/10.1080/10413200305394

Ntoumanis, N., \& Biddle, S. J. (1998). The Relationship of Coping and Its Perceived Effectiveness to Positive and Negative 
Effect in Sport. Personality and Individual Differences, 24, 773-788. http://dx.doi.org/10.1016/S0191-8869(97)00240-7

Ntoumanis, N., Biddle, S. J., \& Haddock, G. (1999). The Mediating Role of Coping Strategies on the Relationship between Achievement Motivation and Affect in Sport. Anxiety, Stress, and Coping, 12, 299-327. http://dx.doi.org/10.1080/10615809908250480

Rusting, C. L., \& Nolen-Hoeksema, S. (1998). Regulating Responses to Anger: Effects of Rumination and Distraction on Angry Mood. Journal of Personality and Social Psychology, 74, 790-803. http://dx.doi.org/10.1037/0022-3514.74.3.790

Sell, H., \& Nagpal, R. (1992). Assessment of Subjective Well-Being: The Subjective Well-Being Inventory (SUBI). New Delhi: Regional Office for South-East Asia, World Health Organization.

Suzuki, S., Shimada, H., Miura, M., Katayanagi, K., Umano, R., \& Sakano, Y. (1997). Development of a New Psychological Stress Response Scale (SRS-18) and Investigation of the Reliability and the Validity. Japanese Journal of Behavioral Medicine, 4, 22-29. (In Japanese) http://doi.org/10.11331/ijbm.4.22

Takano, K. \& Tanno, Y. (2008). Development of Japanese-Version Rumination-Reflection Questionnaire. Japanese Journal of Personality, 16, 259-261. (In Japanese) http://doi.org/10.2132/personality.16.259

Takano, K., \& Tanno, Y. (2009). Self-Rumination, Self-Reflection, and Depression: Self-Rumination Counteracts the Adaptive Effect of Self-Reflection. Behaviour Research and Therapy, 47, 260-264. http://doi.org/10.1016/j.brat.2008.12.008

Takano, K., Sakamoto, S., \& Tanno, Y. (2012). Functional and Dysfunctional Self-Focus, Self-Acceptance, and Self-Disclosure. Japanese Journal of Personality, 21, 12-22. (In Japanese) http://doi.org/10.2132/personality.21.12

Trapnell, P. D., \& Campbell, J. D. (1999). Private Self-Consciousness and the Five-Factor Model of Personality: Distinguishing Rumination from Reflection. Journal of Personality and Social Psychology, 76, 284-304.

http://dx.doi.org/10.1037/0022-3514.76.2.284 